\title{
Evaluation of the Selectivity and Cysteine Dependence of Inhibitors across the Regulator of G Protein-Signaling Family $\$$
}

\author{
Michael P. Hayes, ${ }^{1}$ Christopher R. Bodle, ${ }^{1}$ and David L. Roman \\ Department of Pharmaceutical Sciences and Experimental Therapeutics University of lowa (M.P.H., C.R.B., D.L.R.) and Cancer \\ Signaling and Experimental Therapeutics Program, Holden Comprehensive Cancer Center, University of lowa Hospitals and \\ Clinics (D.L.R.), lowa City, lowa
}

Received July 7, 2017; accepted October 16, 2017

\begin{abstract}
Since their discovery more than 20 years ago, regulators of $\mathrm{G}$ protein-signaling (RGS) proteins have received considerable attention as potential drug targets because of their ability to modulate $\mathrm{G} \alpha$ activity. Efforts to identify small molecules capable of inhibiting the protein-protein interactions between activated $\mathrm{G} \alpha$ subunits and RGS proteins have yielded a substantial number of inhibitors, especially toward the well studied RGS4. These efforts also determined that many of these small molecules inhibit the proteinprotein interactions through covalent modification of cysteine residues within the RGS domain that are located distal to the $\mathrm{G} \alpha$ binding interface. As some of these cysteine residues are highly conserved within the RGS family, many of these inhibitors display
\end{abstract}

activity toward multiple RGS family members. In this work, we sought to determine the selectivity of these small-molecule inhibitors against 12 RGS proteins, as well as against the cysteine-null mutants for 10 of these proteins. Using both biochemical and cellbased methods to assess $\mathrm{G} \alpha$-RGS complex formation and $\mathrm{G} \alpha$ enzymatic activity, we found that several previously identified RGS4 inhibitors were active against other RGS members, such as RGS14, with comparable or greater potency. Additionally, for every compound tested, activity was dependent on the presence of cysteine residues. This work defines the selectivity of commercially available RGS inhibitors and provides insight into the RGS family members for which drug discovery efforts may be most likely to succeed.

\section{Introduction}

The regulators of G protein-signaling (RGS) family, comprising approximately 20 members, terminates $\mathrm{G} \alpha$ signal transduction through their activity as GTPase accelerating proteins (GAP) for activated $\mathrm{G} \alpha$ subunits. This GAP activity is attributed to an approximately 120 -amino-acid region common to all RGS proteins, aptly termed the RGS homology $(\mathrm{RH})$ domain, which directly engages GTP-bound $\mathrm{G} \alpha$. Since their discovery more than 20 years ago, RGS proteins have been considered attractive, but challenging, drug targets because of their ability to modulate signaling cascades occurring through a myriad of $\mathrm{G}$ protein-coupled receptors, including D2 dopamine (Rahman et al., 2003; Ghavami et al., 2004; Mao et al., 2004), $\mu$ opioid (Clark et al., 2003; Wang et al., 2009; Talbot et al., 2010b; Psifogeorgou et al., 2011), 5-HT1A serotonin (Ghavami et al., 2004; Talbot et al., 2010a; Wang et al., 2014), and AT1 angiotensin (Wang et al., 2002; Matsuzaki et al., 2011), to name a few. Because of their effects on signaling downstream of various G protein-coupled receptors, RGS proteins have been

This work was supported by the National Institutes of Health [Grants 5R01CA160470, T32GM067795], University of Iowa College of Pharmacy, and the American Foundation for Pharmaceutical Education.

${ }^{1}$ M.P.H. and C.R.B. contributed equally to this work.

http://doi.org/10.1124/mol.117.109843.

S This article has supplemental material available at molpharm. aspetjournals.org. implicated in numerous disease states, ranging from cancer to disorders of the central nervous system. Several reviews have focused on disease states in which modulation of RGS function could be therapeutically advantageous (Hurst and Hooks, 2009; Roman and Traynor, 2011; Sjogren, 2011).

Because of the potentially beneficial effects of modulating RGS activity, considerable effort has been devoted to identifying inhibitors, particularly of RGS4, one of the most studied and perhaps best understood member of this protein family. Some of the earliest efforts focused on designing cyclic peptides that mimic the regions of $\mathrm{G} \alpha_{\mathrm{i}}$ that bind RGS4, leading to the discovery of the competitive peptide inhibitor YJ34 (Jin et al., 2004). This work further led to the discovery of 5nd, a peptide that covalently modified RGS4 cys residues (Roof et al., 2009), a theme that would become common among RGS4 inhibitors.

As development of peptides into bona fide drugs is challenging, subsequent efforts focused on using high-throughput biochemical screens to identify small-molecule inhibitors of RGS4, the first of which was Center for Chemical Genomics (CCG)4986 (Roman et al., 2007). Follow-up work identified this compound also as being a covalent cys modifier (Kimple et al., 2007), albeit through binding to an allosteric site located distally to the $\mathrm{G} \alpha$-binding face of RGS4 (Roman et al., 2010). In fact, four other RGS4 inhibitors-CCG-63802, CCG-63808, CCG-50014, and CCG-55919 - were found to either interact with cys residues in this same region or exhibit cys-dependent inhibition

ABBREVIATIONS: ANOVA, analysis of variance; CCG, Center for Chemical Genomics; G $\alpha$, guanine nucleotide binding protein, $\alpha$ subunit; GAP, GTPase accelerating proteins; GoLoco, $\mathrm{G} \alpha_{\mathrm{i} / \mathrm{o}}$-Loco domain; NEM, N-ethyl maleimide; PPI, protein-protein interaction; RGS, regulator of $\mathrm{G}$ proteinsignaling protein; $\mathrm{RH}$, RGS homology domain; $\mathrm{WT}, \mathrm{XXX}$. 
(Roman et al., 2009; Blazer et al., 2010, 2011). Previous work by our group identified UI-5 and UI-1590 as RGS4 inhibitors, both of which show lower potency against cys-null RGS4, pointing to a cys-dependent mechanism (Monroy et al., 2013). In addition to the biochemical screening methods that generally measure G $\alpha$-RGS binding or RGS-mediated GAP activity, a recent cell-based screen that measured RGS4's ability to regulate M3 muscarinic receptor activity identified numerous inhibitors, including 6018993, 1777233, 1911669, 6386479, 5428579, and 1472216 (Storaska et al., 2013). Although none of these compounds showed activity against cys-null RGS4, both 1777233 and 5428579 exhibited reversible binding. The chemical structures of all small molecules described here and the references to their discoveries are shown in Table 1.

The $\mathrm{RH}$ domain is composed of nine $\alpha$-helices arranged into two subdomains. The terminal subdomain in made up of helices $1-3,8$, and 9 , and it contains both the $\mathrm{N}$ and $\mathrm{C}$ termini. The bundle subdomain contains helices 4-7, arranged in an antiparallel bundle. The $\mathrm{RH}$ domains tested here contain between zero (RGS6 and RGS7) and four (RGS2 and RGS4) cys residues, and a sequence alignment of the $\mathrm{RH}$ domains with cys residues highlighted is shown in Fig. 1. Notably, the cys residue located at position 95 (highlighted red, Fig. 1B) in RGS4 is conserved except for RGS6 and RGS7, where a Val residue is found. The cys residue at RGS4 position 148 (highlighted purple, Fig. 1B) is somewhat conserved, as it is found in members RGS1, RGS2, RGS4, RGS8, and RGS16.

As different RGS proteins are involved in different signaling pathways, and therefore different physiologic processes as well as potential disease states, we explored the RGS RH domain selectivity profile of previously identified RGS4 inhibitors and the reactivity of the cys residues located in this domain. Given the knowledge that nearly every known small-molecule inhibitor of RGS4 either covalently modifies cys residues or displays cys-dependent activity, we also tested each compound against a cys-null (cys to ala) mutant for every RGS tested.

\section{Materials and Methods}

Compounds. RGS-inhibiting compounds were obtained from commercial sources at indicated purity as follows: 6018993 and 1777223 , both $\geq 95 \%$ purity (Vitas M Laboratories, Champaign, IL); $6383479, \geq 90 \%$ purity (Enamine, Kiev, Ukraine); CCG-50014, $>97 \%$ (Selleck, Houston, TX); CCG-63802, $\geq 98 \%$ (Sigma-Aldrich, St. Louis, MO); UI-5 and UI-1590, both $\geq 95 \%$ (Microsource, Gaylordsville, CT), 5428579 and CCG-4986, both $\geq 95 \%$ (Chembridge, San Diego, CA); CCG-63808, $\geq 97 \%$ (MedChem Express, Monmouth Junction, NJ); N-ethyl maleimide, $\geq 98 \%$ (MP Biomedicals, Santa Ana, CA); DACM, $\geq 95 \%$ (Anaspec, Fremont, CA); 1472216, 98\% (Key Organics, Bedford, MA); 1911669, $\geq 92 \%$ (Pharmeks, Moscow, Russia); CCG-55919, $\geq 90 \%$ (Maybridge Thermo Fisher, Waltham, MA).

TABLE 1

Chemical structures of previously identified inhibitors of RGS Protein family members

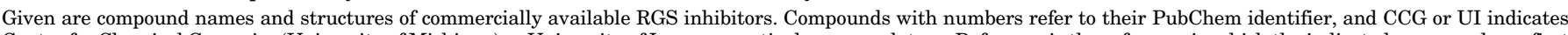

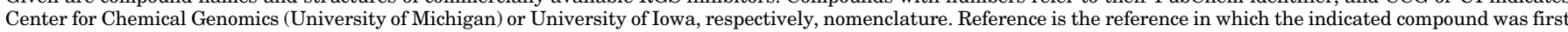
identified. NEM was included for its reactive nature toward cys residues. Dashes indicate that the structures are cys-reactive probe compounds used in this study.

\begin{tabular}{|c|c|c|c|c|c|}
\hline Compound & Structure & Ref. & Compound & Structure & Reference \\
\hline 6018993 & & Storaska et al. (2013) & 5428579 & & Storaska et al. (2013) \\
\hline 1777233 & & Storaska et al. (2013) & CCG-63808 & & Blazer et al. (2010) \\
\hline 1911669 & & Storaska et al. (2013) & CCG-55919 & & Roman et al. (2009) \\
\hline 6383479 & & Storaska et al. (2013) & CCG-4986 & & Roman et al. (2007) \\
\hline CCG-50014 & & Roman et al. (2009) & 1472216 & & Storaska et al. (2013) \\
\hline CCG-63802 & & Blazer et al. (2010) & UI-1590 & & Monroy et al, (2013) \\
\hline UI-5 & & Monroy et al. (2013) & NEM & & - \\
\hline DACM & & - & & & \\
\hline
\end{tabular}


A

RGS1
RGS2
RGS4
RGS5
RGS6
RGS7
RGS8
RGS10
RGS14
RGS16
RGS17
RGS18

\section{RGS1
RGS2
RGS4
RGS5
RGS6
RGS7
RGS8
RGS10
RGS14
RGS16
RGS17
RGS18}

$$
\begin{aligned}
& \text { RGS1 } \\
& \text { RGS2 } \\
& \text { RGS4 } \\
& \text { RGS5 } \\
& \text { RGS6 } \\
& \text { RGS7 } \\
& \text { RGS8 } \\
& \text { RGS10 } \\
& \text { RGS14 } \\
& \text { RGS16 } \\
& \text { RGS17 } \\
& \text { RGS18 }
\end{aligned}
$$

\section{B}
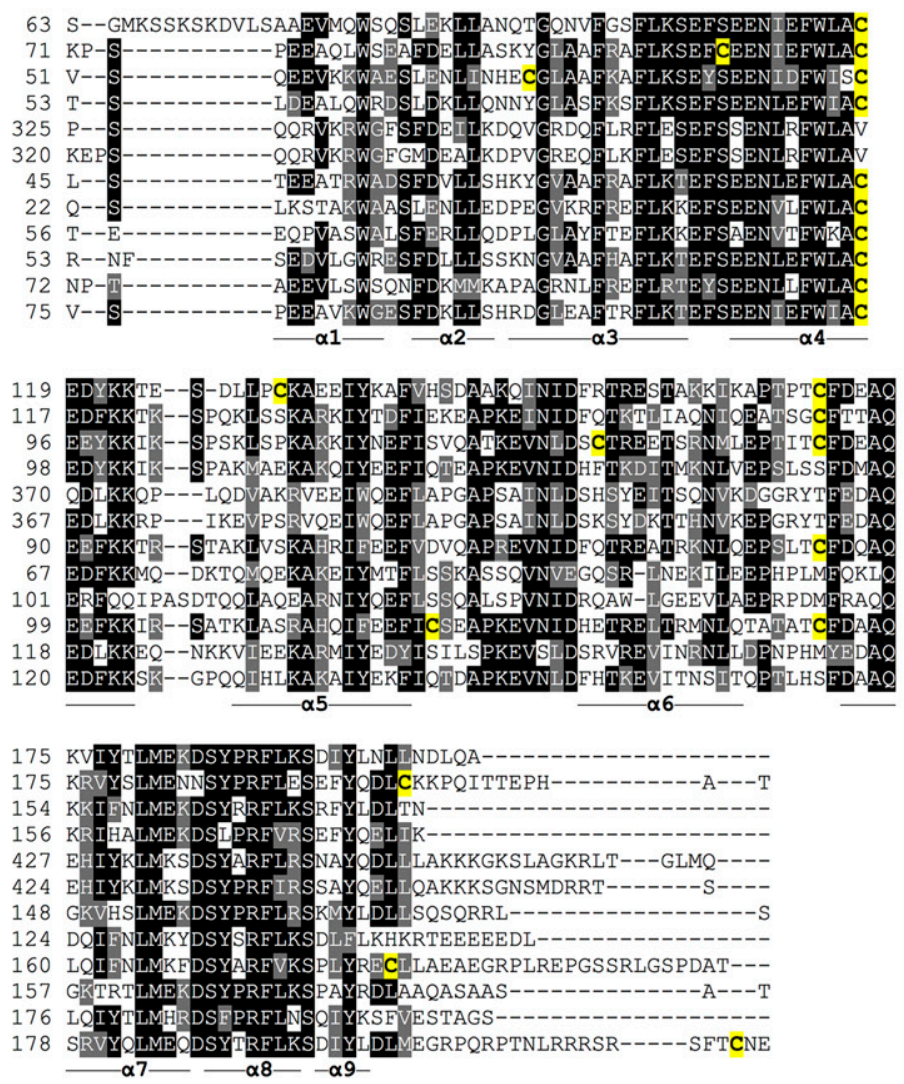

$1,2,4$,
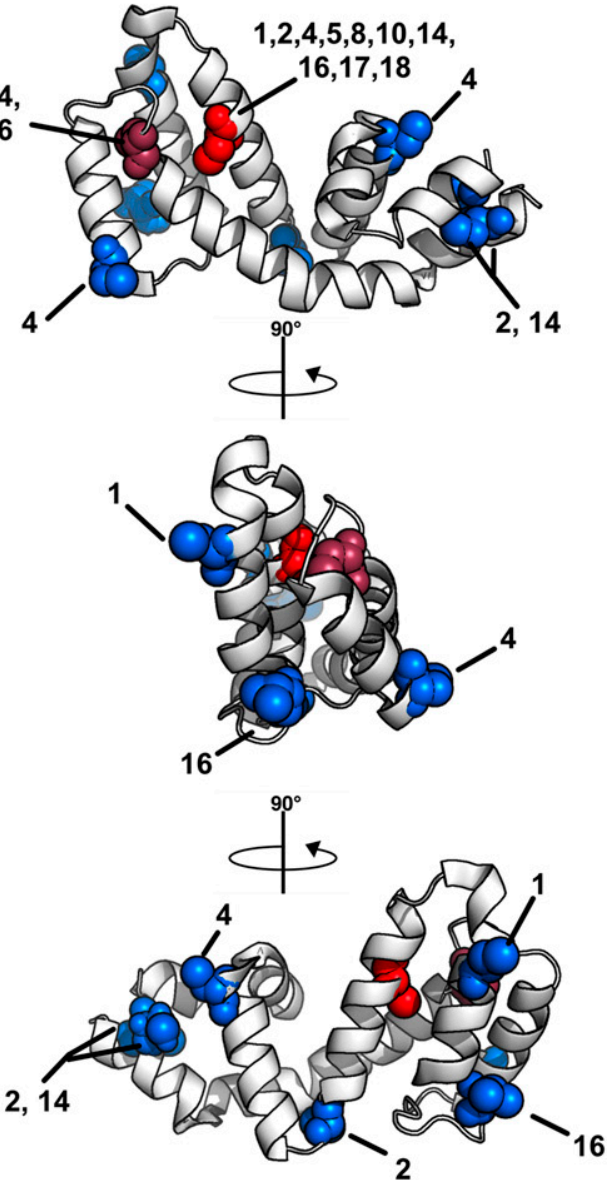

Fig. 1. Conservation of cysteine residues among RGS family members tested. (A) Sequence alignment of the RGS RH domain constructs tested in this study with conserved residues indicated in black, similar residues in gray, and cys residues highlighted in yellow. Residue numbers for full-length RGS proteins are indicated at the beginning of each row, with $\alpha$ helix numbers located beneath, based on G $\alpha_{i 1}$-bound RGS4 (1AGR). (B) Conservation of cys residues as spheres mapped to RGS structure with RGS family members containing relevant residue indicated. Blue represents not or very weakly conserved residues, purple somewhat conserved (RGS4 cys148), and red highly conserved (RGS4 cys 95).

Plasmid Construction. WT-RGS protein constructs were a gift from Nicola Burgess-Brown [Addgene plasmid no. 39143 (RGS1), 38812 (RGS2), 38932 (RGS6), 38813 (RGS7), 38805 (RGS8), 39138 (RGS10), 39139 (RGS14), 39140 (RGS16), 39141 (RGS17), and 39142 (RGS18)]. Human RGS5 residues 52-185 and rat RGS4 residues 51-179 were cloned into pNIC-Bsa4 (Addgene no. 26103; gift from Opher Gileadi), as previously described (Savitsky et al., 2010). Cys-null mutants were obtained by purchasing G Blocks (Integrated DNA Technologies, Coralville, IA) containing RGS coding sequences with all cys mutated to Ala (GCG codon), which were then cloned into pNIC-Bsa4 (Addgene no. 26103), as previously described (Savitsky et al., 2010). All RGS constructs were designed to code for the RGS RH domains with an N-terminal TEV protease-cleavable 6X-His tag.

Protein Purification. All RGS proteins were transformed into BL21-CodonPlus(DE3)-RIPL cells, and colonies were selected and grown at $37^{\circ} \mathrm{C}$ in Terrific Broth until an $\mathrm{OD}_{600}$ of 2.0 , induced with $1 \mathrm{mM}$ IPTG and grown for 16 hours at $18^{\circ} \mathrm{C}$ while shaking at $275-300 \mathrm{rpm}$. Cells were pelleted, resusupended in $50 \mathrm{mM}$ HEPES, $500 \mathrm{mM} \mathrm{NaCl}, 1 \mathrm{mM}$ $\beta$-ME, $10 \mathrm{mM}$ imidazole $\mathrm{pH} 8$ (buffer A), lysed with lysozyme and DNAse $\mathrm{I}$, and subjected to multiple freeze-thaw cycles in liquid $\mathrm{N}_{2}$. Lysates were clarified by centrifugation at $100,000 \mathrm{~g}$, supernatant separated from insoluble pellet, and supernatant subjected to immobilized metal affinity chromatography (Ni Sepharose 6 Fast Flow; GE Healthcare, Chicago, IL). Fractions containing RGS protein were then treated with His-tagged TEV protease and dialyzed overnight at $4^{\circ} \mathrm{C}$ against buffer $\mathrm{A}$ to cleave $6 \mathrm{X}$-His tag. Samples were again subjected to immobilized metal affinity chromatography and flow-through collected, resulting in $>90 \%-95 \%$ purity as determined using SDS-PAGE (Supplemental Fig. S1). Ratealtered mutant $\mathrm{hG} \alpha_{\mathrm{i} 1}$ (R178M, A326S) and $\mathrm{rG} \alpha_{0}$-GST were purified as previously described (Monroy et al., 2013).

Chemical Biotinylation of RGS RH Domains. RGS proteins were biotinylated using EZ-link NHS-Biotin (Thermo Scientific, Waltham, MA) per manufacturer protocol with either 10:1, 5:1, or 3:1 molar excess biotin reagent and incubated on ice for 2 hours. Coupling reaction was quenched with the addition of $5 \times$ molar excess glycine, and RGS proteins were dialyzed overnight against buffer A to remove excess glycine and biotin.

AlphaScreen Protein-Protein Interaction Assay. Biotinylated RGS was conjugated to streptavidin coated donor bead at $9 \mathrm{X}$ desired protein concentration and $135 \mathrm{ng} / \mu \mathrm{l}$ bead in Assay Buffer (20 mM HEPES, $100 \mathrm{mM} \mathrm{NaCl}, 1 \%$ BSA, $1 \%$ Lubrol, pH 8) on ice. After 30 minutes of conjugation the RGS/bead mixture was diluted to $3 \mathrm{X}$ desired concentration and added to 384-well plates (Corning 3824; Corning Scientific, Corning, NY) containing 3X concentration compound and incubated at RT. Separately, GST-G $\alpha_{o}$ was conjugated to anti-GST acceptor beads at $90 \mathrm{nM}$ protein and $135 \mathrm{ng} / \mu \mathrm{l}$ bead in assay buffer on ice. After 20 minutes of conjugation, a portion of the $\mathrm{G}$ protein/bead mixture was removed and diluted to $30 \mathrm{nM}$ protein in assay buffer. This represents the negative control. The remaining $\mathrm{G}$ protein/bead mixture was diluted to $30 \mathrm{nM}$ in assay buffer supplemented with $5 \mathrm{mM} \mathrm{NaF}, 5 \mathrm{mM} \mathrm{MgCl}_{2}, 5 \mu \mathrm{M} \mathrm{AlCl}_{3}$, and $2.5 \mathrm{mM} \mathrm{GDP}$. This mixture was incubated for an additional 10 minutes on ice before 
being added to the appropriate wells of the assay plate. Final concentrations were $1 \times$ for RGS, $10 \mathrm{nM}$ for $\mathrm{G} \alpha_{0}$, and $15 \mathrm{ng} / \mu \mathrm{l}$ for each bead. Assay was incubated for 1 hour at room temerature before measurement on an Envision plate reader (PerkinElmer). All WT-RGS proteins were tested at $10 \mathrm{nM}$ final. Cys-null RGS1 and RGS14 were tested at 31.6 and $100 \mathrm{nM}$, respectively, as these concentrations were necessary to achieve an acceptable difference between positive and negative control wells (data not shown).

RGS-G $\alpha_{i 1}$ GAP Activity Assay (Malachite Green Phosphate Detection). Malachite green free phosphate detection assay was performed largely as described previously (Monroy et al., 2013). For assessment of RGS protein activity, RGS protein was diluted in half-log serial dilutions concentrations ranging from $3.16 \mu \mathrm{M}$ to $3.16 \mathrm{nM}$. For compound dose-response experiments, RGS protein concentration was normalized to each RGS protein's respective $\mathrm{EC}_{80}$, as determined above.

WT-RGS Cysteine DACM Reactivity. Proteins were exhaustively dialyzed against $50 \mathrm{mM}$ HEPES, $500 \mathrm{mM} \mathrm{NaCl}$ at the indicated $\mathrm{pH}$ to remove $\beta$-ME, which can directly interact with DACM, and $20 \mu \mathrm{l}$ of $2 \mu \mathrm{M}$ RGS protein was then added to black 384-well plate (Corning 3575 ), followed by $20 \mu \mathrm{l}$ of $2 \mu \mathrm{M}$ DACM (Anaspec), and fluorescence intensity continuously monitored on Envision plate reader (PerkinElmer, Waltham, MA) for 1500 seconds with excitation and emission wavelengths of 385 and $440 \mathrm{~nm}$, respectively.

NanoBit Protein Complementation Assay. The NanoBit complementation assay was performed as previously described, with minor modifications as described here (Bodle et al., 2017). NanoGlo Live Cell Reagent was prepared as a $5 \times$ stock and added to wells of the assay plate at $10 \mu \mathrm{l} / \mathrm{well}$. Baseline was established for 30 minutes, after which vehicle or $\mathrm{AlF}_{4}$ (stock solution: $40 \mathrm{mM} \mathrm{NaF}, 500 \mu \mathrm{M} \mathrm{AlCl}_{3}$ ) was added to wells at $10 \mu \mathrm{l} /$ well, and assay plate was read for an additional 30 minutes. A $4 \times$ stock of compound or DMSO was added to appropriate wells, and plate was then read for an additional hour. All reads on a Synergy 2 plate reader (BioTek, Winooski, VT) at $37^{\circ} \mathrm{C}$.

Data Analysis. All data were analyzed using Prism 7 (GraphPad, San Diego, CA). For AlphaScreen and malachite green experiments, $\mathrm{IC}_{50}$ values were generated on the combined data set. The mean value of duplicate wells for each independent experiment was determined, and these values from $n \geq 3$ independent experiments were combined in a single table to generate the mean \pm S.D. values reported. Concentrationresponse curves were generated by a single fit on the combined mean \pm S.D. data using $\log$ (inhibitor) versus response, variable slope (four parameter) fit. Data are normalized such that the absence of inhibitor was set to $100 \%$ in each assay. For AlphaScreen, $0 \%$ was normalized to the absence of GDP- $\mathrm{AlF}_{4}$, which is the negative control for proteinprotein interaction (PPI) formation. Absence of RGS represented the negative control and the $0 \%$ normalization for malachite green GAP activity. After normalization, the top and bottom of each curve were constrained to $100 \%$ and $0 \%$, respectively. $\mathrm{IC}_{50}$ values were calculated in Prism software, such that the $\mathrm{IC}_{50}$ is the concentration at which the curve crosses the $50 \%$ plane on the graph. Any calculated $\mathrm{IC}_{50}$ value outside the range of concentrations (up to $100 \mu \mathrm{M}$ ) tested was identified as being $>100 \mu \mathrm{M}$. The $95 \%$ confidence intervals were calculated by GraphPad Prism 7 using the asymmetric (likelihood) method on the single concentration response curve fit of the combined data set (mean \pm S.D. data) described previously. Calculation of statistical significance was performed via one-way analysis of variance (ANOVA) with a Dunnett's multiple comparisons post hoc analysis.

\section{Results}

WT and Cys-Null RGS RH Domains Have GAP Activity. To ensure that both the previously described and novel WT and cys-null RGS constructs produced active protein after purification (Supplemental Fig. S1), the GAP activity of each RGS protein for $\mathrm{G} \alpha_{\mathrm{i} 1}$ was assessed using the previously described malachite green colorimetric assay (Fig. 2) (Monroy et al., 2013). Briefly, this assay measures the GTPase activity of $\mathrm{G} \alpha$, by monitoring the cleavage of the $\gamma$ phosphate group of GTP by $\mathrm{G} \alpha_{\mathrm{i} 1}$ (R178M, A326S). R178M mutation leads to decreased intrinsic GTPase activity of $\mathrm{G} \alpha \alpha_{i 1}$ without effecting RGS sensitivity, making phosphate release RGS-dependent (Berman et al., 1996). A326S mutation increases the rate of GDP release after cleavage of the $\gamma$ phosphate, the ratelimiting step in the $\mathrm{G} \alpha$ cycle, leading to receptor-independent
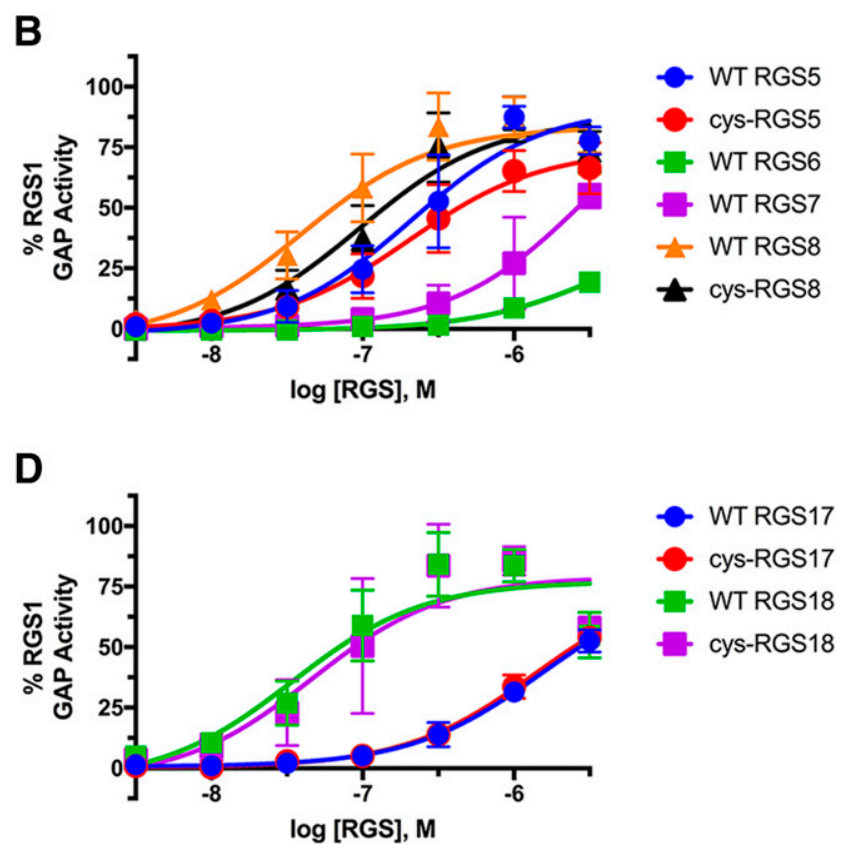

A

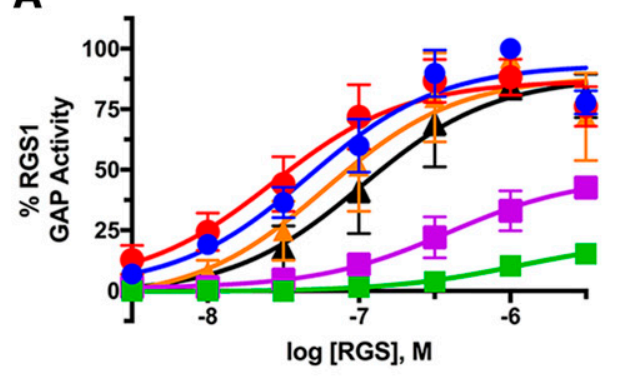

C

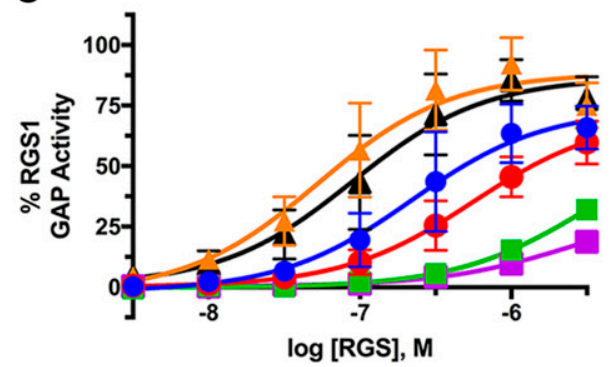

WT RGS1 cys-RGS1 WT RGS2 cys-RGS2 WT RGS4 cys-RGS4

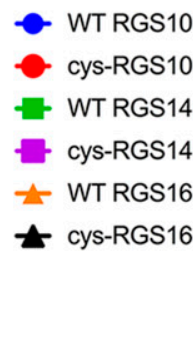

Fig. 2. GAP activity of recombinant WT and Cys-null RH domains (A-D). Assessment of the concentration response curve of GAP activity of both WT and mutant RH domains of indicated RGS family members using malachite green colorimetric assay to measure GTP hydrolysis. (A) WT and Cys-null RGS1, RGS2, and RGS4. (B) WT and Cys-null RGS5, RGS6, RGS7, and RGS8. (C) WT and Cys-null RGS10, RGS14, and RGS16. (D) WT and Cys-null RGS17 and RGS18. Data were normalized to no RGS $(0 \%)$ and the maximal GAP activity of RGS1 (100\%). Data represent mean \pm S.D. from $n=3$ experiments. 
GTP binding by G $\alpha$ (Posner et al., 1998). For WT proteins, all $\mathrm{RH}$ domains increased free phosphate concentration above baseline to an appreciable degree, although RGS2 and RGS6 reached only $21 \%$ and $46 \%$ of the maximal observed activity (1 $\mu$ M RGS1), respectively. For RGS2, this was expected, as it couples preferentially with $\mathrm{G} \alpha_{\mathrm{q}}$ in biochemical assays (Soundararajan et al., 2008). The RGS2 cys-null mutant exhibited greater potency (wild type [WT] $=1100 \mathrm{nM}$, cysnull $=390 \mathrm{nM})$ and greater maximal GAP activity $(\mathrm{WT}=21 \%$, cys-null $=47 \%$ ). For RGS1, RGS4, RGS16, RGS17, and RGS18, WT and cys-null mutants had $\mathrm{EC}_{50}$ values overlapping at the $95 \%$ confidence interval and no appreciable difference in the maximal GAP activity observed. RGS5 WT and cys-null had overlapping $\mathrm{EC}_{50}$ values, but a slight decrease in maximal activity was observed in the cys-null mutant (92\% WT vs. $74 \%$ cys-null). RGS8 WT exhibited more potent GAP activity than cys-null, as the observed $\mathrm{EC}_{50}$ increased from 40 to $95 \mathrm{nM}$, although no differences were observed in the maximal activity. This was also true for RGS10, as the cys-null mutant exhibited an $\mathrm{EC}_{50}$ value (560 nM) that was more than 2-fold greater than WT (220 nM). The RGS14 mutant's maximal GAP activity was only half that of WT RGS14 (33\% vs. 64\%), but overlapping $\mathrm{EC}_{50}$ values were observed.

RGS-G $\alpha_{o}$ PPI Inhibition by Compounds Using AlphaScreen. To assess the selectivity of known RGS inhibitors against a panel of 12 WT and 10 cys-null mutant RGS proteins, we used the AlphaScreen PPI platform. Each WT RGS exhibited a signal window of at least 9-fold or better over negative control, whereas each mutant exhibited a signal window of 4-fold or better over negative control. WT and mutant RGS2 exhibited no binding to $\mathrm{G} \alpha_{\mathrm{o}}$ (data not shown). A panel of 13 known small-molecule RGS inhibitors and one known cys reactive molecule were tested for the ability to inhibit the panel of 22 RGS proteins using AlphaScreen. All compounds used in this study were first discovered as inhibitors of RGS4. Compounds and reference in which they were first discovered are shown in Table 1. N-ethylmaleimide (NEM) was also included, as it is a known cys-reactive compound with inhibitory activity toward RGS4 (Blazer et al., 2011). IC $_{50}$ values with the $95 \%$ confidence index (CI) range for each compound against each RGS are shown in Table 2 (with corresponding concentrationresponse curves in Supplemental Fig. S2); 6018993 did not demonstrate inhibition of any RGS tested, and NEM demonstrated only minimal inhibition of RGS4 and RGS8. These results are excluded from Table 2 for clarity but are presented in Supplemental Table 1. Additionally, some WT RGS proteins were refractory to inhibition by any compound tested. For RGS6 and RGS7, no appreciable inhibition was observed with any compound, and RGS18 was inhibited by only a single compound (CCG-50014). All other WT RGS proteins investigated resulted in at least two compounds producing a calculable $\mathrm{IC}_{50}$, defined as both the upper and lower limit of the 95\% CI, were below the maximum concentration tested $(100 \mu \mathrm{M})$. NEM produced calculable $\mathrm{IC}_{50}$ values for only RGS8 and RGS4. This result aligns with previous reports that RGS4 is sensitive to inhibition by NEM at high concentrations $\left(\mathrm{IC}_{50} 30 \mu \mathrm{M}\right)$ but not iodoacetamide (Blazer et al., 2011), indicating that a degree of substructure specificity or adduct size requirement is involved in the inhibition of RGS proteins by small molecules and that simple covalent modification of cys is not sufficient to impart inhibition.

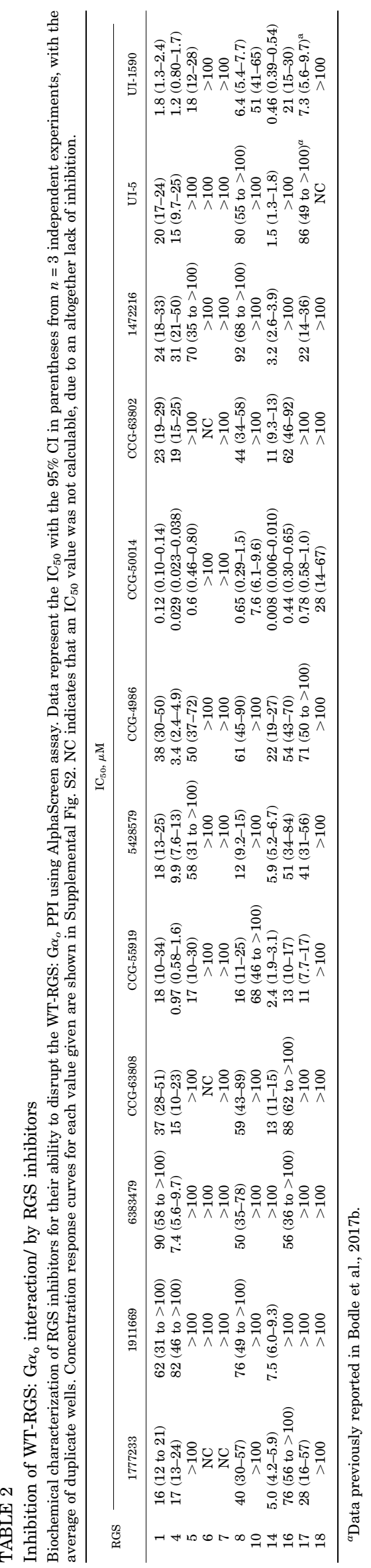


Furthermore, some differences between inhibition were observed in our paradigm and previous reports in the literature. Our results differ from the reports by Storaska et al. (2013) with respect to inhibition and selectivity of RGS7 and RGS8. Compound 1777233, which did not inhibit RGS8 in an FCPIA assay, resulted in inhibition in our assay. Compounds 1911669 and 5428579 were reported to inhibit RGS7, but not RGS8; but our results indicate that these compounds inhibit RGS8 but not RGS7. Compound 6383479 did not inhibit RGS8 or RGS16 using FCPIA (Storaska et al., 2013); however, we report inhibition of both proteins using AlphaScreen. It is possible that these differences can be attributed to differences in methods of FCPIA and AlphaScreen, such as incubation time, buffering conditions, RGS protein concentrations, or the amount of "active" RGS protein in the protein batch used for a given experiment.

The panel of compounds was also tested for activity against the cys-null mutant of each RGS (Supplemental Fig. S2; Table 3). Except for compounds CCG-55919 and CCG-50014, every compound was inactive $\left(\mathrm{IC}_{50}>100 \mu \mathrm{M}\right)$ against cys-null mutants (values excluded from Table 3 for clarity). Only cysnull RGS14 was somewhat inhibited by CCG-55919 and CCG50014 , albeit at a drastically reduced potency (39-fold reduced potency CCG-55919, 5000-fold reduced potency CCG-50014). This result was as expected given the published reports detailing the activity of these compounds against cys-null RGS4.

RGS14 is More Sensitive to Small Molecule Inhibition than RGS4. One of the most striking results of this investigation is that although each small molecule investigated (NEM excluded) was discovered as inhibitor of RGS4, 8 of the 13 were selective for RGS14 RH at the 95\% CI, whereas another (CCG-62808) was equipotent for RGS4 and RGS14 at the $95 \%$ CI. One of these compounds, CCG-50014, was previously identified as one of the most potent RGS4 inhibitors found to date, with an $\mathrm{IC}_{50}$ of $30 \mathrm{nM}$ (Blazer et al., 2011); however, the result of this investigation demonstrates that CCG-50014 inhibits RGS14 with an $\mathrm{IC}_{50}$ of $8 \mathrm{nM}$ and is selective for RGS14 at the $95 \%$ CI.

Several other compounds demonstrated moderate selectivity for RGS14 over other RGS proteins. For example, considering the UI series compounds, UI-5 was 10 times more potent for RGS14 over the next RGS, and UI-1590 inhibited RGS14 with submicromolar potency, whereas the next closest RGS was inhibited with low micromolar potency. In fact, of the 11 compounds that demonstrated inhibition of RGS14, only three (CCG-63808, CCG-4986, and CCG-55919) were not selective for RGS14 over all other RGS proteins. The apparent selectivity of these tested compounds for RGS14 is not a trait that is shared by fellow R12 family member RGS10, as only three compounds had calculable $\mathrm{IC}_{50}$ values for RGS10. This holds true for the R4 family as well, as 11 of 13 compounds resulted in calculable $\mathrm{IC}_{50}$ values against RGS4, whereas only one (CCG-50014) resulted in a calculable $\mathrm{IC}_{50}$ for $\mathrm{R} 4$ family member RGS18.

RGS GAP Activity Inhibition by Compounds. Having established a biochemical pharmacological profile for known RGS inhibitors in a protein-protein interaction assay, we assessed whether the same trends would hold true in a secondary, functional biochemical assay. RGS6, RGS7, RGS10, and RGS18 were excluded due to minimal inhibition in AlphaScreen assay. Although RGS14 was readily inhibited
TABLE 3

Inhibition of Cys-Null RGS: G $\alpha_{\mathrm{o}}$ interaction by RGS inhibitors Biochemical characterization of RGS inhibitors for their ability to disrupt the cys-null RGS: $\mathrm{G} \alpha_{o}$ PPI using AlphaScreen assay. Data represent the $\mathrm{IC}_{50}$ with the $95 \% \mathrm{CI}$ in parentheses from $n=3$ independent experiments, each with duplicate wells. Concentration-response curves are shown in Supplemental Fig. S2. All compounds from Table 2 were tested, and any compounds for which all cys-null RGS proteins exhibited $>100 \mu \mathrm{M} \mathrm{IC}_{50}$ values were excluded from this table.

\begin{tabular}{ccc}
\hline & \multicolumn{2}{c}{$\mathrm{IC}_{50}, \mu \mathrm{M}(95 \% \mathrm{CI})$} \\
\cline { 2 - 3 } & $\mathrm{CCG}-55919$ & CCG-50014 \\
\hline 1 & $>100$ & $>100$ \\
4 & $>100$ & $>100$ \\
5 & $>100$ & $>100$ \\
8 & $>100$ & $>100$ \\
10 & $>100$ & $>100$ \\
14 & $94(60$ to $>100)$ & $>100$ \\
16 & $>100$ & $>100$ \\
17 & $>100$ & $>100$ \\
18 & $>100$ & \\
\hline
\end{tabular}

by many of the compounds, it was excluded because $80 \%$ maximal activity could not be observed at up to $10 \mu \mathrm{M}$ final protein concentration (Fig. 2C). As no cys-null mutants were sensitive to small-molecule inhibition in AlphaScreen, none were included.

Trends observed in the free phosphate detection assay were comparable to those observed in the protein-protein interaction assay (Fig. 3; Table 4). Compound 5428579 is not included in Table 4, as no RGS protein inhibition was observed in this assay. RGS1 and RGS4 were the most susceptible to inhibition in this assay, with six compounds resulting in calculable $\mathrm{IC}_{50}$ values for each protein. Additionally, CCG-63808 and CCG50014 resulted in overlapping $\mathrm{IC}_{50}$ values for RGS1 and RGS4 at the $95 \%$ CI in this assay, where they were not overlapping in the AlphaScreen assay (Table 2). In general, for RGS1 and RGS4, the potencies of the compounds were comparable between the two assays.

This was not the case for the other four RGS proteins tested. CCG-50014 exhibited high nanomolar potencies for RGS5, RGS8, RGS16, and RGS17 using AlphaScreen but demonstrated reduced potencies in the free phosphate detection assay. Similar results were obtained for CCG-55919, as this compound resulted in low micromolar potencies using AlphaScreen and yet resulted in $\mathrm{IC}_{50}$ values of greater than $100 \mu \mathrm{M}$ in this GAP activity assay, possibly owing to higher protein concentrations (micromolar) required to measure GAP activity, whereas much lower concentrations (nanomolar) are needed to measure RGS: G $\alpha$ interaction using AlphaScreen. Alternatively, this could be caused by each assay using different $\mathrm{G} \alpha$ subunits, as AlphaScreen uses $\mathrm{G} \alpha_{o}$ and the GAP assay a mutant of $\mathrm{G} \alpha_{\mathrm{i} 1}$ with accelerated GTP-binding activity. Additionally, this could be a phenomenon dependent on which RGS family member is being evaluated.

RGS RH Domains Show Marked Differences in Cysteine Reactivity. Because RGS inhibitors display little activity toward cys-null mutants, we sought to determine whether the relative potencies of these inhibitors were directly related to the intrinsic reactivity of their cys residues. For this assessment, we used the cys-reactive dye DACM, which has appreciable fluorescence only once it has covalently labeled cys residues in proteins (Fig. 4; Table 5). By treating the WT-RGS proteins with a 1:1 molar ratio of DACM, we observed drastically different reaction rates 
A

CCG-63808

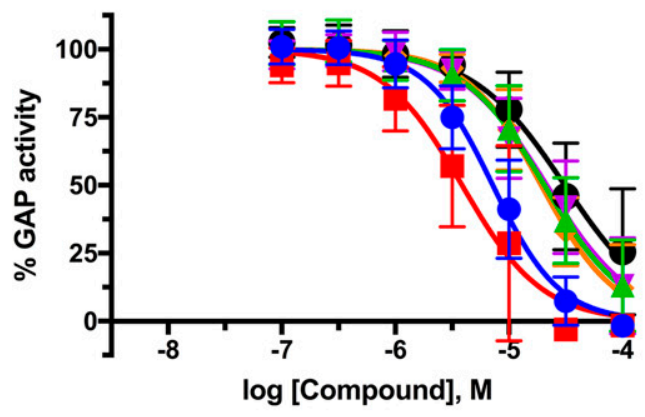

C

CCG-55919

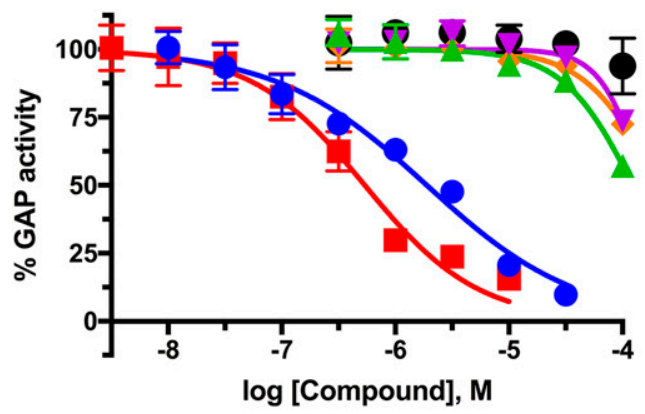

$\mathbf{E}$

CCG-4986

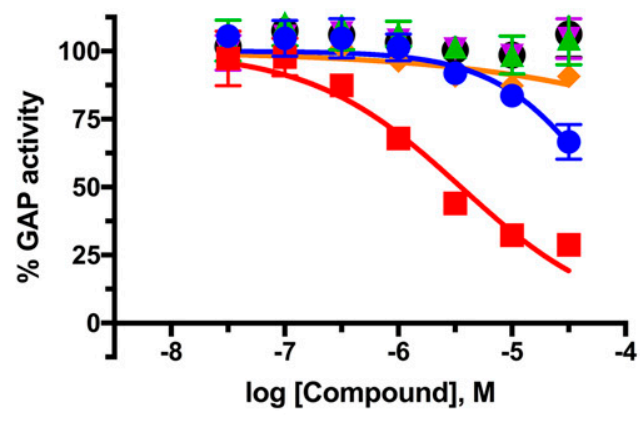

G

$$
\text { UI-1590 }
$$

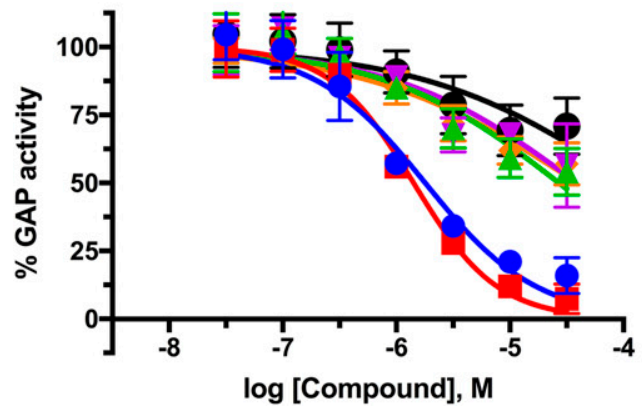

B CCG-50014

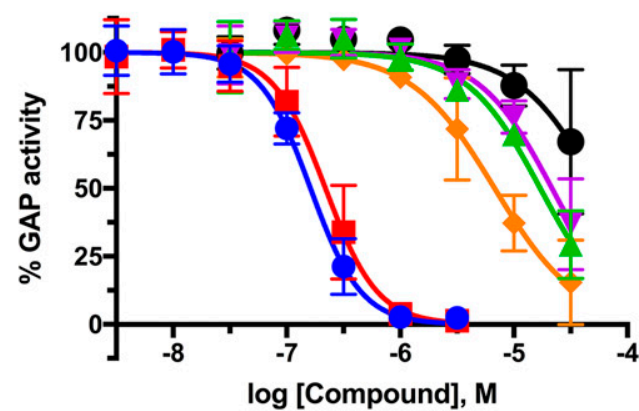

D CCG-63802

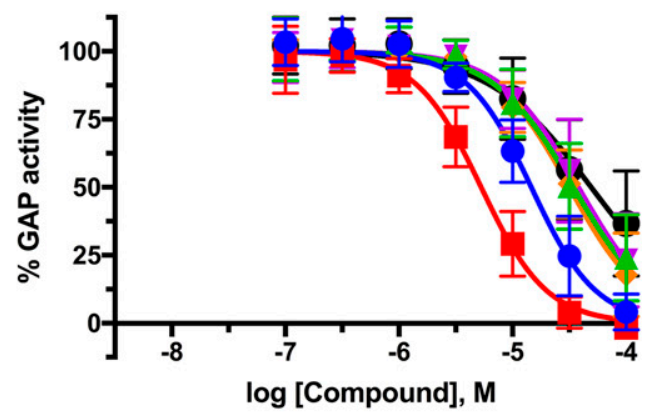

F

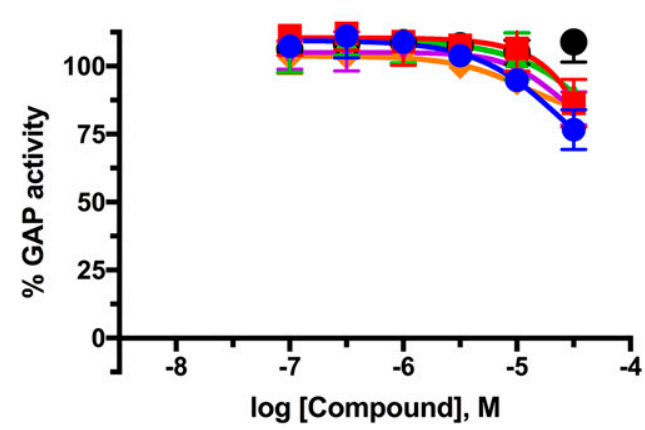

RGS1

- RGS4

+ RGS5

* RGS8

RGS16

RGS17

Fig. 3. Inhibition of WT RGS RH domain GAP activity by small molecules (A-G). Concentration-response assessment of the indicated inhibitor's effect on WT RGS RH domain GAP activity using malachite green colorimetric assay to measure GTP hydrolysis. Data represent mean \pm S.D. from $n=3$ independent experiments and are summarized in Table 4.

across the RGS family, which could be grossly categorized as those that readily react with DACM, those that are moderately reactive, and those that are not reactive. Independent of $\mathrm{pH}$ tested, RGS1, RGS2, RGS4, RGS16, and RGS18 were modified by DACM to a level that was appreciably greater than either buffer alone or the cys-devoid RGS6 and RGS7. An intermediate level of reactivity was observed for RGS14 at each pH tested and RGS10 at pH 7.0 and 6.5 but not at pH 7.5. Alternatively, RGS5, RGS8, and RGS17 interacted with DACM minimally. At every pH tested, RGS18, which 
TABLE 4

Inhibition of WT-RGS GAP activity at hG $\alpha_{\mathrm{i} 1}(\mathrm{R} 178 \mathrm{M}, \mathrm{A} 326 \mathrm{~S})$

Biochemical characterization of RGS inhibitors for their ability to disrupt the GAP activity of WT-RGS RH domains using phosphate detection assay to monitor $\mathrm{G} \alpha$ GTPase activity using $\mathrm{hG} \alpha_{\mathrm{i} 1}$ (R178M, A326S) rapid turnover mutant. Data represent the $\mathrm{IC}_{50}$ with the $95 \% \mathrm{CI}$ in parentheses from $n=3$ independent experiments, each with duplicate wells. Concentration response curves are shown in Fig. 3 . NC indicates that an IC $\mathrm{C}_{50}$ value was not calculable owing to a complete lack of inhibition.

\begin{tabular}{rlccccc}
\hline \multirow{2}{*}{ RGS } & \multicolumn{5}{c}{$\mathrm{IC}_{50}, \mu \mathrm{M}(95 \%$ CI $)$} \\
\cline { 2 - 7 } & CCG-63808 & CCG-55919 & CCG-4986 & CCG-50014 & CCG-63802 & UI-1590 \\
\hline 1 & $7.2(5.7-9.1)$ & $1.9(1.5-2.4)$ & $64(43$ to $>100)$ & $0.16(0.14-0.19)$ & $15(12-18)$ & $1.8(1.3-2.5)$ \\
4 & $3.9(2.4-6.0)$ & $0.54(0.41-0.71)$ & $3.6(2.6-4.9)$ & $0.22(0.18-0.27)$ & $5.3(4.3-6.5)$ & $1.4(1.2-1.7)$ \\
5 & $20(15-28)$ & $>100$ & NC & $17(14-22)$ & $34(25-48)$ & $27(16-58)$ \\
8 & $22(16-30)$ & $>100$ & NC & $22(17-28)$ & $38(28-52)$ & $39(21$ to $>100)$ \\
16 & $19(15-25)$ & $>100$ & $>100$ & $6.8(5.2-8.9)$ & $32(25-40)$ & $40(25-74)$ \\
17 & $31(21-46)$ & NC & NC & $55(35$ to $>100)$ & $49(32-84)$ & $>100$ \\
\hline
\end{tabular}

contains two cys residues, was the fastest to react, although it did not display the highest relative intensity value. The next fastest rate observed was for RGS4 followed by RGS1, with RGS4 displaying lower $t_{1 / 2}$ and higher relative fluorescence at every $\mathrm{pH}$ tested, possibly because RGS4 has four cys residues versus three in RGS1. The next most reactive $\mathrm{RH}$ domain belonged to RGS16, which reacted approximately four times slower than RGS4 at $\mathrm{pH}$ 7.5, and 7.0. RGS2 reacted similarly to RGS16 at pH 7.5 but was approximately 2 -fold slower at $\mathrm{pH}$ 7.0. Although the rate of reaction of RGS14's two cys residues was slow (displaying an approximately linear rate), it was able to produce appreciable fluorescence at every $\mathrm{pH}$, as was RGS10 at $\mathrm{pH} 6.5$ and 7.0. Alternatively, RGS5, RGS8, and RGS17 showed only minimal interaction with DACM. RGS5 (one cys) reacted nearly half as fast as RGS8 (two cys residues), although, paradoxically, the $t_{1 / 2}$ values for both proteins did not decrease with increasing $\mathrm{pH}$, as would be predicted. RGS10 and RGS17 both only have calculable $t_{1 / 2}$ values at $\mathrm{pH} 7.5$ as a result of the curve shape, although the magnitude of these reactions (fluorescence intensity) is so low that they may be of limited relevance.
A

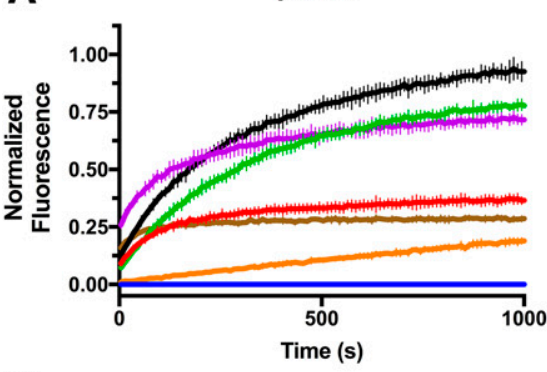

D

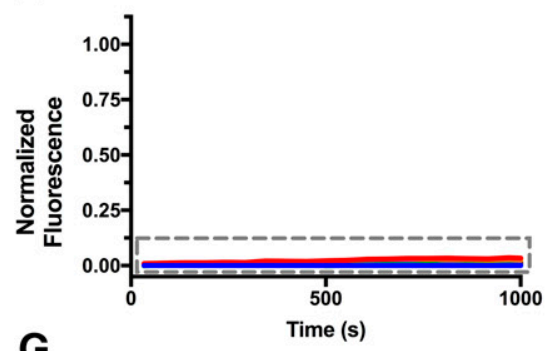

G

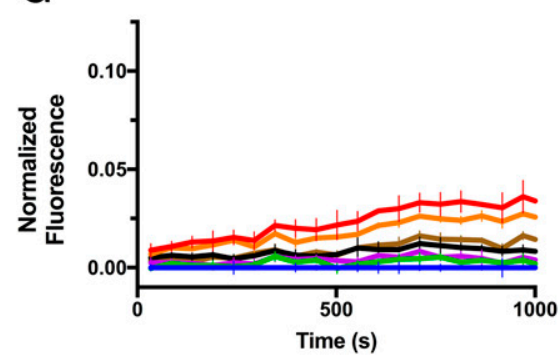

B

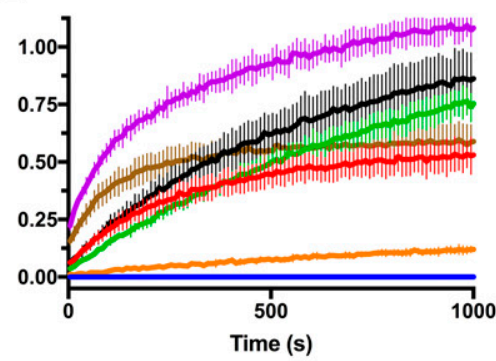

E

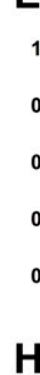

1.00
0.75
0.50
0.25
0.00
$\mathrm{H}$

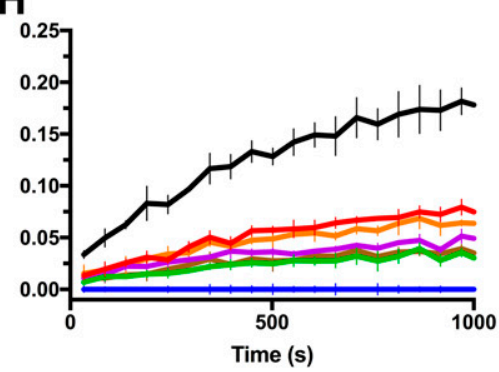

C

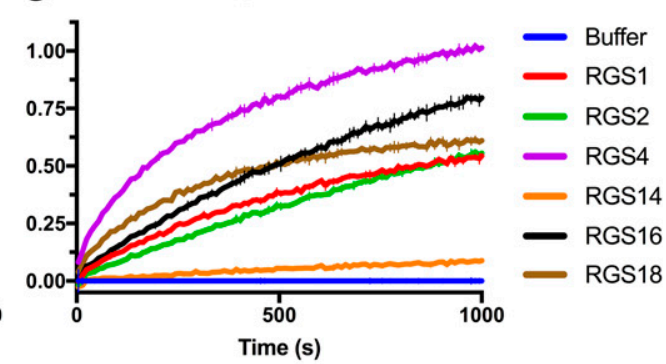

$F$

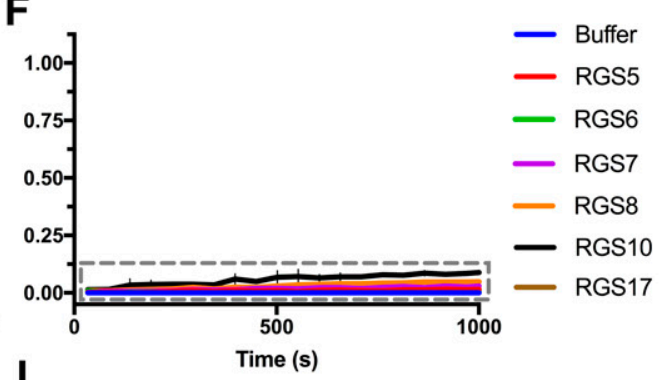

I

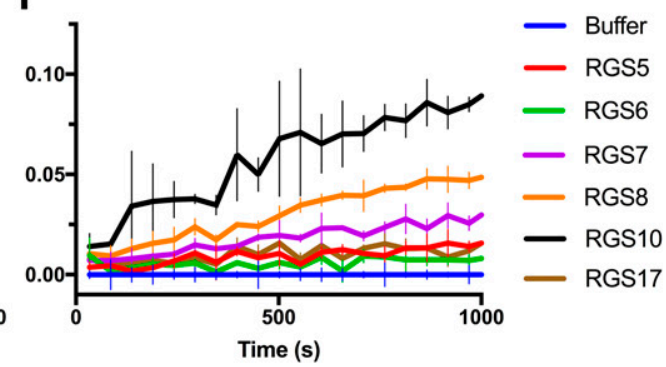

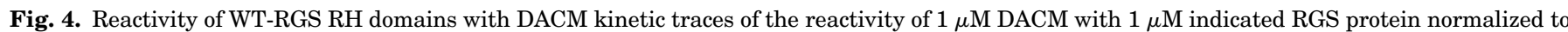

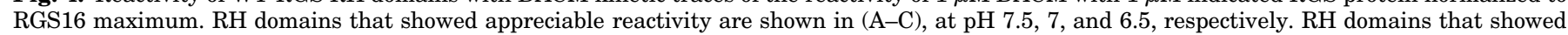

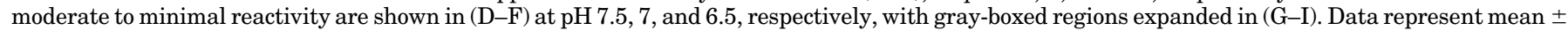
S.D. from $n=3$ independent experiments. Time to half-maximal reactivity $\left(t_{1 / 2}\right)$ is summarized in Table 5 . 
TABLE 5

Cysteine reactivity of RGS RH domains with DACM

Summary of RGS RH domain reactions with the environmentally sensitive maleimide dye DACM from kinetic traces shown in Fig. 4. Data represent mean time $t_{1 / 2}$ as determined via fit to one phase association with the $95 \%$ CI in parentheses from $n=3$ independent experiments. n.d. indicates reactivity that was undistinguishable from RGS6 and RGS7, which lack cys residues. $\mathrm{t}_{1 / 2}, \mathrm{~s}(95 \% \mathrm{CI})$

\begin{tabular}{ccccc}
\hline RGS & No. of Cys Residues & $\mathrm{pH} 7.5$ & $\mathrm{pH} 7.0$ & $\mathrm{pH} \mathrm{6.5}$ \\
\hline 1 & 3 & $74(69-80)$ & $225(218-232)$ & $762(742-781)$ \\
2 & 4 & $275(269-282)$ & $1170(1140-1200)$ & $>1000$ \\
4 & 4 & $61(55-68)$ & $150(139-162)$ & $316(302-331)$ \\
5 & 1 & $830(591-1200)$ & $614(508-746)$ & n.d. \\
8 & 2 & $531(355-799)$ & $476(390-583)$ & $>1000$ \\
10 & 1 & n.d. & $472(414-539)$ & $>1000$ \\
14 & 2 & $>1000$ & 71000 & $>1000$ \\
16 & 3 & $224(216-233)$ & $623(605-641)$ & $>1000$ \\
17 & 1 & n.d. & $361(263-495)$ & n.d. \\
18 & 2 & $10(9-12)$ & $59(56-63)$ & $244(237-251)$ \\
\hline
\end{tabular}

Compounds 6383479 and CCG-63802 Inhibit RGS Proteins in Cells. Using a cell-based split NanoLuciferase (NanoLuc) system, we assessed the ability of several compounds to inhibit the interaction of $\mathrm{G} \alpha \alpha_{\mathrm{i} 1}$ with RGS proteins in cells. In this assay, one PPI binding partner is tagged with an $18-\mathrm{kD}$ fragment of NanoLuc and the other binding partner a $1.3 \mathrm{kD}$ NanoLuc peptide. Formation of PPI results in formation of a competent NanoLuc, and luminescence is recorded.

This system was used to test 6383479 , CCG-4986, CCG50014, and CCG-63802 against RGS1, RGS4, RGS8, RGS14, RGS16, and cys-null RGS4 with $\mathrm{G} \alpha_{i 1}$. These compounds were chosen based on the combined criteria of potency, known activity in cells and/or in vivo, and apparent RGS selectivity based on AlphaScreen and/or GAP activity results. Whereas CCG-4986 and CCG-50014 did demonstrate inhibition of several RGS proteins in this assay, this inhibition was not significantly different from the inhibition of the assay itself, as determined using a control PPI (Supplemental Fig. S3), such that no conclusions about the activity of these compounds in cells can be made. Compound 6383479 demonstrated a significant difference in signal means as determined via oneway ANOVA $(F(7,16)=10.37, P<0.001)$. Dunnett's post hoc multiple comparisons analysis revealed that RGS1, RGS4, RGS14, and cys-null RGS4 were inhibited by 6383479 to a significant degree compared with PPI control $(P=0.03$, $<0.001,<0.001$, and 0.023, respectively) whereas RGS8 and RGS16 were not. The most robust inhibition was observed for RGS4 (Fig. 5A).

Compound CCG-63802 also demonstrated a significant difference in signal means as determined via one-way ANOVA $(F(7,16)=13.4, P<0.001)$. Dunnett's multiple comparisons analysis revealed RGS1, RGS4, and RGS14 were inhibited by CCG-63802 to a significant degree compared with PPI control $(P=0.031, P<0.001$, and $P<0.001$, respectively), whereas RGS8, RGS16, and cys-null RGS4 were not. For CCG-63802, the most robust inhibition was observed for RGS4, then RGS14, and then RGS1. Slight inhibition was also observed for RGS8, RGS16, and cys-null RGS4, although not to a statistically significant degree (Fig. 5B).

This cell-based system was also amenable to the RGS2-G $\alpha_{\mathrm{q}}$ PPI. Of the four compounds tested, two inhibited RGS2 in cells (Fig. 5). Compounds 6383479 and CCG-63802 reduced the signal of the RGS2- G $\alpha_{\mathrm{q}}$ interaction to roughly $35 \%$ and $19 \%$ of DMSO-treated controls, respectively, representing a statistically significant deviation from the control PPI (determined via one-way ANOVA as already described). Dunnett's multiple comparison $P$ vales for each were as follows: compound $6383479, P=0.001$ and compound CCG-63802, $P<0.001$. CCG-4986 and CCG-50014 did not result in inhibition of RGS2-G $\alpha_{\mathrm{q}}$ that was discernable from their effects on the assay as was observed with $\mathrm{G} \alpha_{\mathrm{i} 1}$ (Supplemental Fig. S3, A-C).
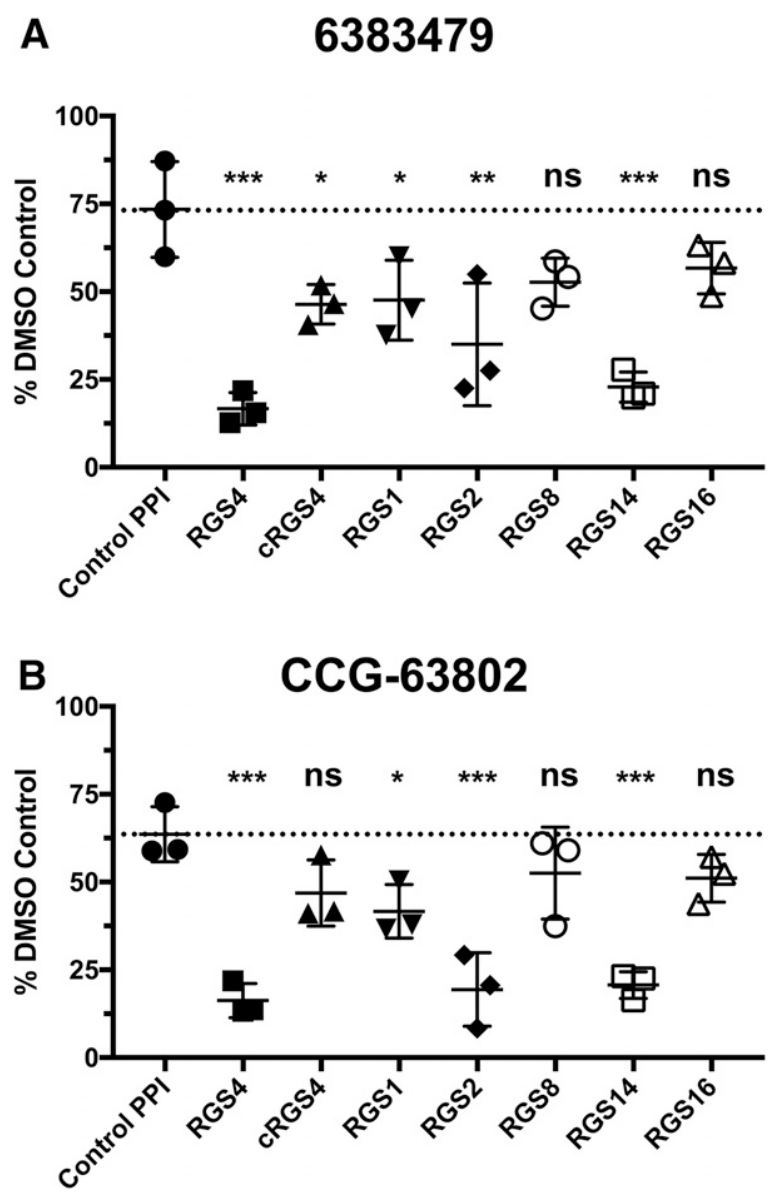

Fig. 5. Inhibition of RGS: G $\alpha$ interaction in cells. NanoBiT luminescence complementation assay in HEK293T cells expressing indicated RGS and $\mathrm{G} \alpha_{\mathrm{i} 1}$ (except RGS2 with $\mathrm{G} \alpha_{\mathrm{q}}$ ). Decrease in signal in response to compound treatment as a percentage of vehicle treatment of $31.6 \mu \mathrm{M} 6383479(\mathrm{~A})$ and $31.6 \mu \mathrm{M}$ CCG-63802 (B). Data represent $n=3$ independent experiments in at least duplicate \pm S.D. Statistical significance determined via one ANOVA with Dunnett's multiple comparisons test with respect to control PPI. $P$ values on graph are reflective of multiple comparisons results: ${ }^{*} P<0.05 ;{ }^{* *} P<0.01 ; * * * P<0.001 ;$ ns, not significant. 


\section{Discussion}

Here we present an investigation of a panel of known RGS4 inhibitors against a panel of $12 \mathrm{WT}$ and 10 cys-null mutant RGS proteins, establishing the most comprehensive pharmacologic profile of these inhibitors for RGS proteins to date. Additionally, we investigated the intrinsic RGS property of cys reactivity to potentially elucidate why certain compounds are more potent against certain RGS proteins.

Investigation of 13 known RGS4 inhibitors resulted in the identification of at least one inhibitor for 10 of the 12 WT RGS proteins, with only RGS6 and RGS7 demonstrating a lack of inhibition. For RGS1, RGS2, RGS5, RGS10, RGS14, and RGS18, this represents the first identification of small molecules that inhibit these RGS proteins. Each of these RGS proteins have been directly implicated in specific pathologies (reviewed in Hurst and Hooks, 2009) or have been suggested to play a yet unverified role in pathologies (Evans et al., 2015). Therefore, through the identification of smallmolecule inhibitors of these proteins, this work has provided tool compounds that may be used to probe the consequence of pharmacologic inhibition of these RGS proteins in their respective disease states. Perhaps the most powerful such tool will be CCG-50014, which we demonstrated inhibits RGS1, RGS5, RGS8, RGS14, RGS16, and RGS17 with submicromolar potency and has reported activity in mouse models in vivo in the investigation of RGS4 (Yoon et al., 2015). Additionally, our data greatly expand the RGS pharmacologic profile for these compounds and establishes a more comprehensive examination of compound/RGS selectivity.

The revelation that many of the small-molecule inhibitors tested were selective for the RH domain of RGS14 over that of RGS4 was surprising, as previous reports detailing the discovery of these compounds all demonstrated selectivity for RGS4. Perhaps one of the most surprising of these was CCG-50014, which was previously identified as one of the most potent small-molecule inhibitors of RGS proteins to date, with an $\mathrm{IC}_{50}$ of $30 \mathrm{nM}$ against RGS4 (Roman et al., 2009; Blazer et al., 2011). This compound was found to be a more potent inhibitor of RGS14, with an $\mathrm{IC}_{50}$ of $8 \mathrm{nM}$ and no overlap in $\mathrm{IC}_{50}$ with RGS4 at the $95 \% \mathrm{CI}$. This, along with the result that many of the compounds were selective for RGS14, establishes the RH domain of RGS14 as highly sensitive to small molecule inhibition compared with the other RGS proteins tested, warranting further investigation as a target.

Given that the investigated compounds exhibited cys dependence in the reports characterizing their initial discoveries, it was not surprising that all the compounds exhibited cys dependence for all the RGS proteins. This finding led us to investigate whether the newly established pharmacologic profile with respect to these RGS proteins could be attributed to the number of cys in the RH domain of these RGS proteins. Aside from the complete absence of cys in the RH domain, the number of cys residues in the RH domain does not correlate to the potency of inhibition; there are several examples of this. RGS14 was often inhibited with the greatest potency, and yet it contains only two cys residues compared with RGS4, which contains four. Additionally, RGS18 contains two cys, one of which is highly conserved among RGS proteins and yet was only susceptible to inhibition by CCG-50014. Compare that with RGS17, which contains only one cys residue (also residing in this highly conserved region) and is inhibited by eight of the compounds tested. This led us to hypothesize that it is not the number of cys residues but rather distinct structural characteristics of the RGS proteins that alter the accessibility, and thus the reactivity of the cys residues, and that cys accessibility would correlate to observed potency of these compounds; however, our assessment of the accessibility of cys residues via use of the dye DACM demonstrates that this is not the case. In these experiments, neither the magnitude of fluorescence nor the rate of signal increase correlated to the newly established pharmacologic profile of inhibition of RGS proteins via these small molecules. This is likely because these small molecules are interacting with specific cys residues or a specific subset of cys residues in the RGS protein. Therefore, identification of the critical cys residues required for inhibition and assessment of those resides for cys accessibility may yield more interesting results. For example, RGS10 and RGS14 are closely related, as both reside in the R12 family and share $>52 \%$ identity within the RH domain. RGS14 contains an additional cys residue near its $\mathrm{C}$ terminus in $\alpha 9$ and is readily inhibited by many of the compounds tested, whereas RGS10 lacks this residue and is inhibited by only three of the compounds tested, each with $\mathrm{IC}_{50}>7 \mu \mathrm{M}$. This provides some preliminary evidence that this $\mathrm{C}$-terminal cys residue may be an important determinant for inhibitor specificity. An RGS14 construct in which the only cys present is the highly conserved cys residue in $\alpha 4$ could be a useful tool in future studies aimed at further understanding the molecular determinants of RGS inhibition.

Additionally, it is possible that some other structural features of the RGS RH domains confer the small-molecule selectivity established here, such as protein dynamics or altered $\mathrm{pK}_{\mathrm{a}}$ values of critical cys residues. It should be noted that this work used the RH domains of all RGS proteins tested, and yet many RGS proteins are larger and more complex, containing additional domains that are sites of posttranslational modification or are responsible for $\mathrm{G}$ proteinindependent signaling cascades. The work here is critical in the investigations of variations within the $\mathrm{RH}$ domain that result in susceptibility to small-molecule inhibition among RGS proteins; however, investigation using the full-length constructs would shed light on the selectivity of these compounds in a more physiologically representative system, particularly for RGS family members that possess more complex multidomain and multifunctional properties. For example, many of the small-molecule inhibitors tested here were more selective for RGS14 over other RGS proteins; however, RGS14 contains a $\mathrm{G} \alpha_{\mathrm{i} /} /$ Loco interaction (GoLoco) domain that acts as a guanosine nucleotide dissociation inhibitor and prevents dissociation of GDP from the G $\alpha$ subunit. Thus, the GoLoco motif adds another level of regulation of $\mathrm{G} \alpha_{\mathrm{i} / \mathrm{o}}$ signaling for RGS14 (Kimple et al., 2001; Willard et al., 2004). As such, the consequence of RGS14 RH inhibition on the net regulation of $\mathrm{G} \alpha$ signaling in a physiologic system (i.e., using full-length RGS14) needs to be assessed.

Finally, we established a cell-based pharmacological profile for a subset of compounds using our previously characterized protein complementation assay (Bodle et al., 2017). The differential inhibition of RGS proteins observed suggests that this system may be used for the establishment of a more detailed cell based pharmacologic profile for both these and future RGS small-molecule inhibitors. 
In conclusion, we have established a more comprehensive RGS pharmacologic profile for 13 published RGS4 inhibitors against a panel of 12 RGS proteins, which represents roughly $60 \%$ of the RGS family. Ten RGS proteins now have at least one identified small-molecule inhibitor that may be used as a tool compound to probe RGS function. The revelation that many small molecules inhibited RGS14 with greater potency than RGS4 demonstrates the need for more comprehensive examination of small-molecule promiscuity among RGS proteins in future discovery efforts. This work, combined with future structural interrogation, will be the foundation for establishment of RGS models that allow for design of RGSspecific small-molecule inhibitors.

\section{Acknowledgments}

The University of Iowa High Throughput Screening facility provided instrumentation, and Joseph P. O'Brien assisted in cloning and participated in helpful discussions.

\section{Authorship Contributions}

Participated in research design: Hayes, Bodle, Roman.

Conducted experiments: Hayes, Bodle.

Contributed new regents or analytic tools: Hayes, Bodle, Roman.

Performed data analysis: Hayes, Bodle, Roman.

Wrote or contributed to writing of manuscript: Hayes, Bodle, Roman.

\section{References}

Berman DM, Wilkie TM, and Gilman AG (1996) GAIP and RGS4 are GTPaseactivating proteins for the Gi subfamily of G protein alpha subunits. Cell 86: $445-452$.

Blazer LL, Roman DL, Chung A, Larsen MJ, Greedy BM, Husbands SM, and Neubig RR (2010) Reversible, allosteric small-molecule inhibitors of regulator of $\mathrm{G}$ protein signaling proteins. Mol Pharmacol 78:524-533.

Blazer LL, Zhang H, Casey EM, Husbands SM, and Neubig RR (2011) A nanomolarpotency small molecule inhibitor of regulator of G-protein signaling proteins. Biochemistry 50:3181-3192.

Bodle CR, Hayes MP, O’Brien JB, and Roman DL (2017) Development of a bimolecular luminescence complementation assay for RGS: G protein interactions in cells. Anal Biochem 522:10-17.

Clark MJ, Harrison C, Zhong H, Neubig RR, and Traynor JR (2003) Endogenous RGS protein action modulates mu-opioid signaling through Galphao. Effects on adenylyl cyclase, extracellular signal-regulated kinases, and intracellular calcium pathways. J Biol Chem 278:9418-9425.

Evans PR, Dudek SM, and Hepler JR (2015) Regulator of G protein signaling 14: a molecular brake on synaptic plasticity linked to learning and memory. Prog $\mathrm{Mol}$ Biol Transl Sci 133:169-206.

Ghavami A, Hunt RA, Olsen MA, Zhang J, Smith DL, Kalgaonkar S, Rahman Z, and Young KH (2004) Differential effects of regulator of G protein signaling (RGS) proteins on serotonin 5-HT1A, 5-HT2A, and dopamine D2 receptor-mediated signaling and adenylyl cyclase activity. Cell Signal 16:711-721.

Hurst JH and Hooks SB (2009) Regulator of G-protein signaling (RGS) proteins in cancer biology. Biochem Pharmacol 78:1289-1297.

Jin Y, Zhong H, Omnaas JR, Neubig RR, and Mosberg HI (2004) Structure-based design, synthesis, and pharmacologic evaluation of peptide RGS4 inhibitors. J Pept Res 63:141-146.

Kimple AJ, Willard FS, Giguère PM, Johnston CA, Mocanu V, and Siderovski DP (2007) The RGS protein inhibitor CCG-4986 is a covalent modifier of the RGS4 Galpha-interaction face. Biochim Biophys Acta 1774:1213-1220.

Kimple RJ, De Vries L, Tronchère H, Behe CI, Morris RA, Gist Farquhar M, and Siderovski DP (2001) RGS12 and RGS14 GoLoco motifs are G alpha(i) interaction sites with guanine nucleotide dissociation inhibitor activity. J Biol Chem 276:29275-29281.
Mao H, Zhao Q, Daigle M, Ghahremani MH, Chidiac P, and Albert PR (2004) RGS17/RGSZ2, a novel regulator of Gi/o, Gz, and Gq signaling. J Biol Chem 279: $26314-26322$.

Matsuzaki N, Nishiyama M, Song D, Moroi K, and Kimura S (2011) Potent and selective inhibition of angiotensin AT1 receptor signaling by RGS2: roles of its N-terminal domain. Cell Signal 23:1041-1049.

Monroy CA, Mackie DI, and Roman DL (2013) A high throughput screen for RGS proteins using steady state monitoring of free phosphate formation. PLoS One 8: e62247.

Posner BA, Mixon MB, Wall MA, Sprang SR, and Gilman AG (1998) The A326S mutant of Gialpha1 as an approximation of the receptor-bound state. J Biol Chem 273:21752-21758.

Psifogeorgou K, Terzi D, Papachatzaki MM, Varidaki A, Ferguson D, Gold SJ, and Zachariou V (2011) A unique role of RGS9-2 in the striatum as a positive or negative regulator of opiate analgesia. $J$ Neurosci 31:5617-5624.

Rahman Z, Schwarz J, Gold SJ, Zachariou V, Wein MN, Choi KH, Kovoor A, Chen CK, DiLeone RJ, Schwarz SC, et al. (2003) RGS9 modulates dopamine signaling in the basal ganglia. Neuron 38:941-952.

Roman DL, Blazer LL, Monroy CA, and Neubig RR (2010) Allosteric inhibition of the regulator of G protein signaling-Galpha protein-protein interaction by CCG-4986. Mol Pharmacol 78:360-365.

Roman DL, Ota S, and Neubig RR (2009) Polyplexed flow cytometry protein interaction assay: a novel high-throughput screening paradigm for RGS protein inhibitors. J Biomol Screen 14:610-619.

Roman DL, Talbot JN, Roof RA, Sunahara RK, Traynor JR, and Neubig RR (2007) Identification of small-molecule inhibitors of RGS4 using a high-throughput flow cytometry protein interaction assay. Mol Pharmacol 71:169-175.

Roman DL and Traynor JR (2011) Regulators of G protein signaling (RGS) proteins as drug targets: modulating G-protein-coupled receptor (GPCR) signal transduction. J Med Chem 54:7433-7440.

Roof RA, Roman DL, Clements ST, Sobczyk-Kojiro K, Blazer LL, Ota S, Mosberg HI, and Neubig RR (2009) A covalent peptide inhibitor of RGS4 identified in a focused one-bead, one compound library screen. BMC Pharmacol 9:9.

Savitsky P, Bray J, Cooper CD, Marsden BD, Mahajan P, Burgess-Brown NA, and Gileadi $O$ (2010) High-throughput production of human proteins for crystallization: the SGC experience. J Struct Biol 172:3-13.

Sjögren B (2011) Regulator of G protein signaling proteins as drug targets: current state and future possibilities. Adv Pharmacol 62:315-347.

Soundararajan M, Willard FS, Kimple AJ, Turnbull AP, Ball LJ, Schoch GA, Gileadi C, Fedorov OY, Dowler EF, Higman VA, et al. (2008) Structural diversity in the RGS domain and its interaction with heterotrimeric G protein alpha-subunits. Proc Natl Acad Sci USA 105:6457-6462

Storaska AJ, Mei JP, Wu M, Li M, Wade SM, Blazer LL, Sjögren B, Hopkins CR, Lindsley CW, Lin Z, et al. (2013) Reversible inhibitors of regulators of G-protein signaling identified in a high-throughput cell-based calcium signaling assay. Cell Signal 25:2848-2855.

Talbot JN, Jutkiewicz EM, Graves SM, Clemans CF, Nicol MR, Mortensen RM, Huang X, Neubig RR, and Traynor JR (2010a) RGS inhibition at G(alpha)i2 selectively potentiates 5-HT1A-mediated antidepressant effects. Proc Natl Acad Sci USA 107:11086-11091.

Talbot JN, Roman DL, Clark MJ, Roof RA, Tesmer JJ, Neubig RR, and Traynor JR (2010b) Differential modulation of mu-opioid receptor signaling to adenylyl cyclase by regulators of G protein signaling proteins 4 or 8 and 7 in permeabilised $\mathrm{C} 6$ cells is Galpha subtype dependent. $J$ Neurochem 112:1026-1034.

Wang Q, Liu M, Mullah B, Siderovski DP, and Neubig RR (2002) Receptor-selective effects of endogenous RGS3 and RGS5 to regulate mitogen-activated protein kinase activation in rat vascular smooth muscle cells. $J$ Biol Chem 277:24949-24958.

Wang Q, Liu-Chen LY, and Traynor JR (2009) Differential modulation of mu- and delta-opioid receptor agonists by endogenous RGS4 protein in SH-SY5Y cells. J Biol Chem 284:18357-18367.

Wang Q, Terauchi A, Yee CH, Umemori H, and Traynor JR (2014) 5-HT1A receptormediated phosphorylation of extracellular signal-regulated kinases (ERK1/2) is modulated by regulator of $\mathrm{G}$ protein signaling protein 19. Cell Signal 26: 1846-1852.

Willard FS, Kimple RJ, and Siderovski DP (2004) Return of the GDI: the GoLoco motif in cell division. Annu Rev Biochem 73:925-951.

Yoon SY, Woo J, Park JO, Choi EJ, Shin HS, Roh DH, and Kim KS (2015) Intrathecal RGS4 inhibitor, CCG50014, reduces nociceptive responses and enhances opioidmediated analgesic effects in the mouse formalin test. Anesth Analg 120:671-677.

Address correspondence to: David L. Roman, The University of Iowa, College of Pharmacy, 115 S Grand Ave., PHAR S327, Iowa City, IA, 52242. E-mail: david-roman@uiowa.edu 